International Journal on Intelligent Electronic System, Vol. 8 No. 2. July 2014

\title{
ENHANCEMENT OF POWER PROFILE USING MC- UNIFIED POWER QUALITY CONDITIONING SYSTEM
}

\author{
A.PRABU1, R.JACOB RAJESH², \\ 1\&2 Fatima Michael College of Engineering and technology, Madurai \\ 1mahaprabume@rediffmail.com, 2rajeshjr20@gmail.com
}

\section{Abstract -}

Voltage sag is a frequently occurring power quality problem as it may significantly affect industrial production. The unified power quality conditioning system is used to mitigate voltage sag under different fault condition. In this paper to study the operation of MC-UPQC system used in distribution system. The main purpose of multi-converter unified power-quality conditioning system (MC-UPQC) is capable of simultaneous compensation for voltage and current imperfection in multibus/multifeeder systems. In this configuration, one shunt voltage-source converter (shunt VSC) and one series VSCs exist. The system can be applied to adjacent feeders to compensate for supply-voltage imperfections. The IEEE 16 node test feeder, which is a highly loaded unbalanced system, is used in the study. The UPQC consists of a three-level inverter with IGBTs and PWM control. Modelling and simulations are implemented in Mat lab/Simulink.

Keywords- multi-converter unified power-quality conditioning system (MC-UPQC), Unified power-quality conditioner (UPQC), voltage sag, voltage-source converter (VSC), Unbalanced Radial Distribution Systems.

\section{I.INTRODUCTION}

Any power problem that results in failure or misoperation of customer equipment manifests itself as an economic burden to the user or produces negative impacts the environment.

Power quality and power system deregulation have become very important concerns for utility, facility and consulting engineers in recent years. Increasing development of nonlinear loads in distribution system is deteriorating power quality and causing disturbance in the operation of many sensitive loads. These problems include a variety of electrical disturbances, which may originate in several ways and have different effects on various kinds of sensitive loads. The commonly occurring power quality problem is Voltage sags, Interruptions, Distortion, Harmonics, Harmonic resonance, Interharmonics, Notching, Noise due to Critical load, and sensitive loads [1]. So we must eliminate above power quality problem different technical options available to improve power quality, active power filters have proved to be an important alternative device to compensate for current and voltage disturbances in power distribution systems. Voltage sag is a frequently occurring power quality problem. Voltage sag is defined as reduction in the root mean square (RMS) voltage in the range of 0.1 to 0.9 per unit for duration greater than half a cycle and less than one minute [1]. The voltage sags cause effects on the performance of sensitive loads. This paper deals with unified power quality conditioners (UPQC's), which aim at the integration of series active and shunt-active filters [6].

The main purpose of a UPQC is to mitigate voltage and current related problems simultaneously. And also compensate for supply voltage flicker/imbalance, reactive power, negative-sequence current, and harmonics. In other words, the UPQC has the capability of improving power quality at the point of installation on power distribution systems or industrial power systems. The instantaneous active and reactive power theory ( $P-Q$ Theory) is widely used to design controllers for active filters.

\section{POWER QUALITY PROBLEMS IN POWER DISTRIBUTION SYSTEMS}

Power quality problems are common in most of commercial, industrial and utility networks. For an electrical distribution system, power quality is the extent to which line voltage is a sine wave of constant amplitude. There are many types of loads such as linear, nonlinear, sensitive and critical loads used in distribution side so that the incidence of harmonic-related problems 
in utility and industrial power systems is increasing [1]. Problems with a utility's generators or distribution system can cause serious power quality problems such as voltage drops and transients, both of which can reduce the life of lighting systems and other electrical equipment. Here considered power quality problems such as voltage sag is shown in fig.1. Voltage sag is a decrease to between 0.1 and 0.9 pu in RMS voltage at the power frequency for durations from 0.5 cycles to one minutes. Voltage sag is not a complete interruption of power; it is a temporary drop below 90 percent of the nominal voltage level. Most voltage sags do not below 50 percent of nominal voltage, they normally last from 3 to 10 cycles or 50 to 170 milliseconds.

Voltage sags and Harmonics are transient events caused by faults (short circuits), transformer energization, motor starting and sudden load changes, all of these phenomena can be classified as low or mid frequency transients.

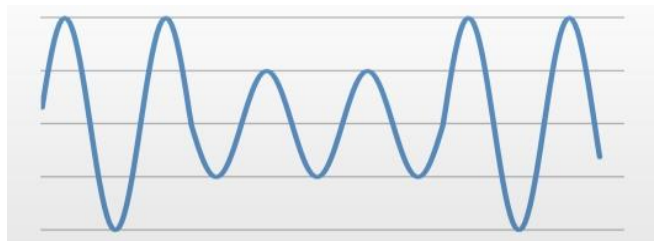

Fig.1 Voltage sags.

The low voltage causes,

1. High current flow through the line for same load causing high line losses.

2. The sustained low voltage causes failure of insulation.

3. Increase heating of lines, transformer and motor.

The IEEE 16 node test feeder, shown in Fig.2 is chosen in order to illustrate the MC-UPQC performance in a highly loaded and unbalanced system. It consists of three-feeder distribution system.

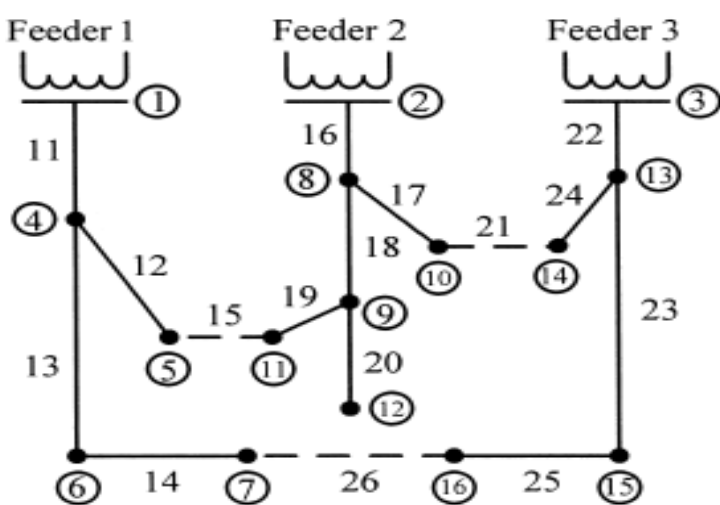

Fig.2 three-feeder distribution Test system for system. TABLE I

LINE AND LOAD DATA FOR THE IEEE 16 NODE TEST FEEDERS

\begin{tabular}{|c|c|c|c|c|c|}
\hline $\begin{array}{l}\text { Selectio } \\
\mathrm{n} \text { bus to } \\
\text { bus }\end{array}$ & $\begin{array}{l}\text { Selecti } \\
\text { on } \\
\text { Resist } \\
\text { ance } \\
\text { (p.u) }\end{array}$ & $\begin{array}{l}\text { Selecti } \\
\text { on } \\
\text { reacta } \\
\text { nce } \\
\text { (p.u) }\end{array}$ & $\begin{array}{l}\text { End } \\
\text { bus } \\
\text { real } \\
\text { load } \\
(\mathrm{M} \\
\mathrm{W})\end{array}$ & $\begin{array}{c}\text { End } \\
\text { bus } \\
\text { reactiv } \\
\text { e } \\
\text { load( } \\
\text { MVA } \\
\text { R) }\end{array}$ & $\begin{array}{c}\text { End } \\
\text { bus } \\
\text { fixed } \\
\text { capaci } \\
\text { tor } \\
\text { (MVA } \\
\text { R) }\end{array}$ \\
\hline $1-4$ & 0.075 & 0.1 & 1.5 & 1.2 & \\
\hline $4-5$ & 0.08 & 0.11 & 4 & 2.7 & \\
\hline $4-6$ & 0.09 & 0.18 & 5 & 3 & 1.2 \\
\hline $6-7$ & 0.04 & 0.04 & 1 & 0.9 & \\
\hline $2-8$ & 0.11 & 0.11 & 0.6 & 0.1 & 0.6 \\
\hline $8-9$ & 0.08 & 0.11 & 4.5 & 2 & 3.7 \\
\hline $8-10$ & 0.11 & 0.11 & 1 & 0.9 & \\
\hline $9-11$ & 0.11 & 0.11 & 1 & 0.7 & 1.8 \\
\hline $9-12$ & 0.08 & 0.11 & 1 & 0.9 & \\
\hline $3-13$ & 0.11 & 0.11 & 2.1 & 1 & 1.8 \\
\hline $13-14$ & 0.09 & 0.12 & & & \\
\hline $13-15$ & 0.08 & 0.11 & & & \\
\hline $15-16$ & 0.04 & 0.04 & & & \\
\hline $5-11$ & 0.04 & 0.04 & & & \\
\hline $10-14$ & 0.04 & 0.04 & & & \\
\hline $7-16$ & 0.12 & 0.12 & & & \\
\hline
\end{tabular}

Input data of this example system are shown in Table 1 . The system consists of 3 feeders, 13 normally 
closed sectionalizing switches, and 3 normally open tie switches. The system load is assumed to be constant and Base $=100 \mathrm{MVA}$.

\section{MITIGATION OF POWER QUALITY PROBLEMS}

A flexible and versatile solution to voltage quality problems is offered by active power filters. Currently they are based on PWM converters and connect to low and medium voltage distribution system in shunt or in series [4]. Generally, an active filter has been considered to be a current source connected in parallel with the load (harmonic source). The approach is based on the principle of injecting harmonic voltage and current into the ac system, of the same amplitude.

Power quality can be improved through:

- Power factor correction,

- Harmonic filtering,

- Special line notch filtering,

- Transient voltage surge suppression,

- Proper earthing systems.

\section{UNIFIED POWER QUALITY CONDITIONER}

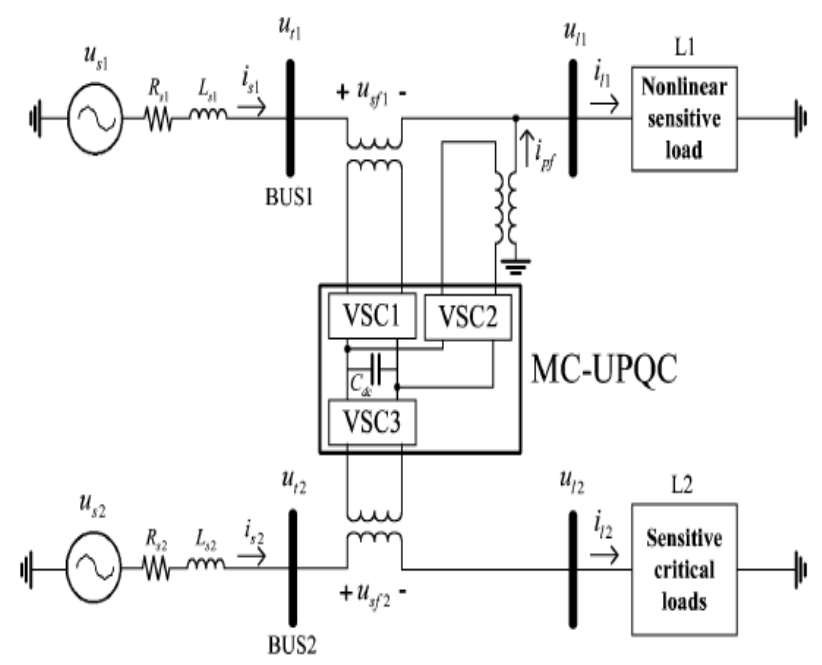

Fig.3: Functional diagram of UPQC

The basic system configuration of a general UPQC consisting of the combination of a series-active and shunt-active filter is shown in fig.3. The main purpose of the series-active filter is harmonic isolation between a sub transmission system and a distribution system. In addition, the series-active filter has the capability of voltage flicker/ imbalance compensation as well as voltage regulation and harmonic compensation at the utility-consumer point of common coupling (PCC).

The main purpose of the shunt active filter is to absorb current harmonics, compensate for reactive power and negative-sequence current, and regulate the dc-link voltage between both active filters. In this paper, the integration of the series-active and shunt active filters is called the UPQC [3].

In the proposed configuration, all converters are connected back to back on the dc side and share a common dc-link capacitor. Therefore, power can be transferred from one feeder to adjacent feeders to compensate for sag/swell and interruption. The performance of the MC-UPQC as well as the adopted control algorithm is illustrated by simulation.

\section{A. SERIES ACTIVE POWER FILTERS}

Series active power filters compensate current system distortion caused by non-linear loads by imposing a high impedance path to the current harmonics which forces the high frequency currents to flow through the LC passive filter connected in parallel to the load. The high impedance imposed by the series active power filter is created by generating a voltage of the same frequency that the current harmonic component that needs to be eliminated. Voltage unbalance is corrected by compensating the fundamental frequency negative and zero sequence voltage components of the system. The series active power filter is shown in fig.4.

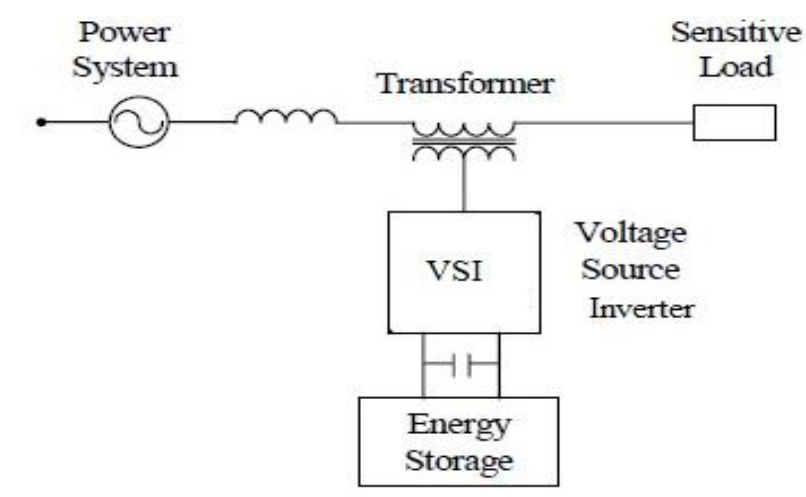

Fig.4. Compensation characteristics of a series power filter.

The Functions of the series VSCs in each feeder are:

1. To mitigate voltage sag and swell. 
2. To compensate for voltage distortions, such a harmonics.

3. To compensate for interruptions.

\section{B. SHUNT ACTIVE POWER FILTERS}

Shunt active power filter compensate current harmonics by injecting equal-but-opposite harmonic compensating current. In this case the shunt active power filter operates as a current source injecting the harmonic components generated by the load but phase shifted by $180^{\circ}$. This principle is applicable to any type of load considered a harmonic source. Moreover, with an appropriate control scheme, the active power filter can also compensate the load power factor. In this way, the power distribution system seen the non linear load and the active power filter as an ideal resistor. The current compensation characteristic of the shunt active power filter is shown in Fig.5.

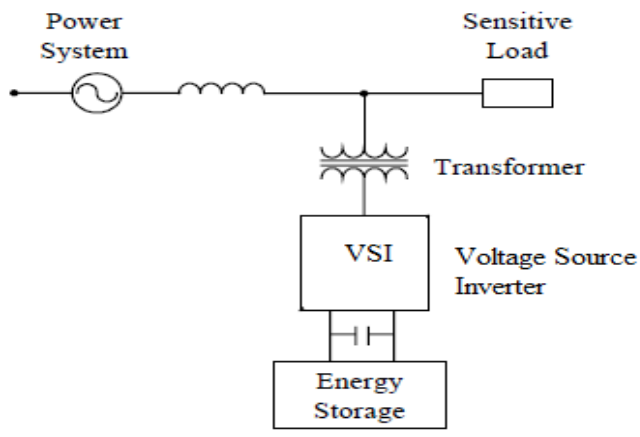

Fig.5. Compensation characteristics of a shunt active power filter.

The Functions of the shunt-VSC are:

1. To compensate reactive component of load current.

2. To compensate harmonic components of load current.

3. To regulate the voltage of the common dc-link capacitor.

\section{CONTROL SCHEME}

Series active and shunt active power filters are normally implemented with pulse-width modulated voltage source inverters. The block diagram of a shunt active power filter control scheme is shown in Fig. 4 .
Control algorithm, which are based on the instantaneous reactive power theory.

\section{A. INSTANTANEOUS PQ THEORY}

The instantaneous active and reactive power theory or the $p-q$ Theory is widely used to design controllers for active filters [7], [8]. The $p-q$ Theory is based on the $a \beta 0$ transformation. Also known as the Clarke Transformation $p-q$ theory consists in a real matrix to transform threephase voltages and currents into the a 0 stationary reference frame. The control circuit of upqc is shown in fig.6. The main advantages of a $\beta 0$ transformation are the separation of zero sequence components into zero sequence axis. (i.e.) No zero sequence current components are present. pq theory based on time domain, it is valid for both steady state and transient operations. The $a \beta 0$ transformation applied to the $a b c$ three phase voltage is,

$$
\left[\begin{array}{l}
V_{0} \\
V_{\alpha} \\
V_{\beta}
\end{array}\right]=\sqrt{\frac{2}{3}}\left[\begin{array}{ccc}
\frac{1}{\sqrt{2}} & \frac{1}{\sqrt{2}} & \frac{1}{\sqrt{2}} \\
1 & \frac{-1}{2} & \frac{-1}{2} \\
0 & \sqrt{\frac{3}{2}} & -\sqrt{\frac{3}{2}}
\end{array}\right]\left[\begin{array}{l}
V_{a} \\
V_{b} \\
V_{c}
\end{array}\right]
$$

The inverse aß0 transformation is,

$$
\left[\begin{array}{l}
V_{a} \\
V_{b} \\
V_{c}
\end{array}\right]=\sqrt{\frac{2}{3}}\left[\begin{array}{ccc}
\frac{1}{\sqrt{2}} & 1 & 0 \\
\frac{1}{\sqrt{2}} & \frac{-1}{2} & \sqrt{\frac{3}{2}} \\
\frac{1}{\sqrt{2}} & \frac{-1}{2} & -\sqrt{\frac{3}{2}}
\end{array}\right]\left[\begin{array}{l}
V_{0} \\
V_{\alpha} \\
V_{\beta}
\end{array}\right]
$$

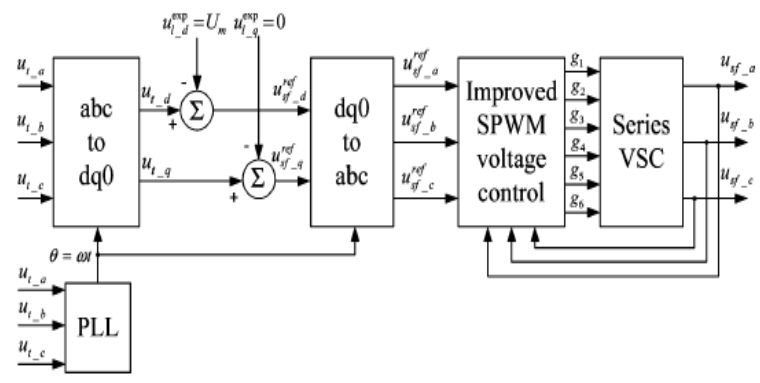

Fig.6. control circuit for UPQC 


\section{B. SPWM TECHNIQUES}

The switching control strategy for series VSCs and the shunt VSC are selected to be sinusoidal pulse widthmodulation (SPWM) voltage control.

The harmonic content in the output of the inverters can be reduced by employing pulse width modulation (PWM). The SPWM is shown in fig.7. The use of power electronic equipments in industrial and consumer applications has been increased in recent years. Such loads draw nonlinear sinusoidal current and voltage from the source resulting in the harmonics in the networks. Sinusoidal PWM (SPWM) is effective in reducing lower order harmonics while varying the output voltage. The gating signals are generated by comparing a sinusoidal reference signal with a triangular carrier wave of frequency.

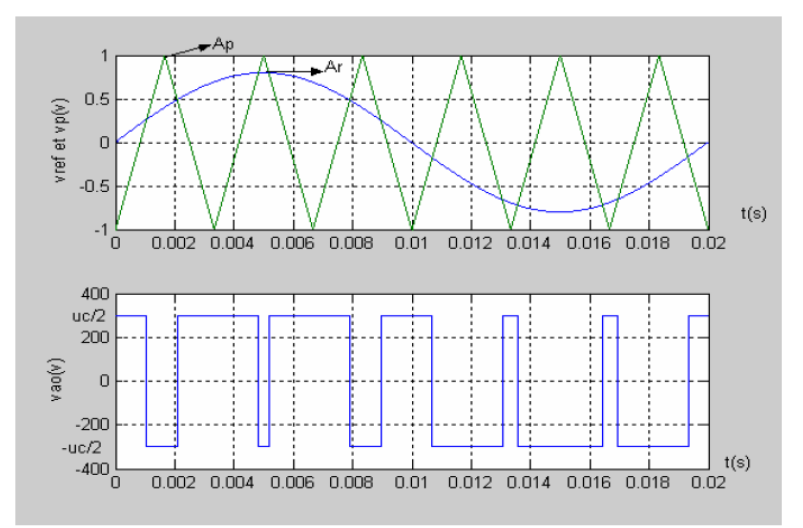

Figure.7. Three phase voltage inverter - Sinusoidal modulation with bidirectional carrying wave.

\section{SIMULATON RESULTS AND DISCUSSION}

The proposed UPQC and its control schemes have been tested. In this section, simulation results are presented, and the performance of the proposed UPQC system is shown in fig.8. The voltage compensation for IEEE 16 Bus Distribution System with UPQC are simulated in matlab/simulink environment. The voltage sag in feeder 1 is shown in fig.8.

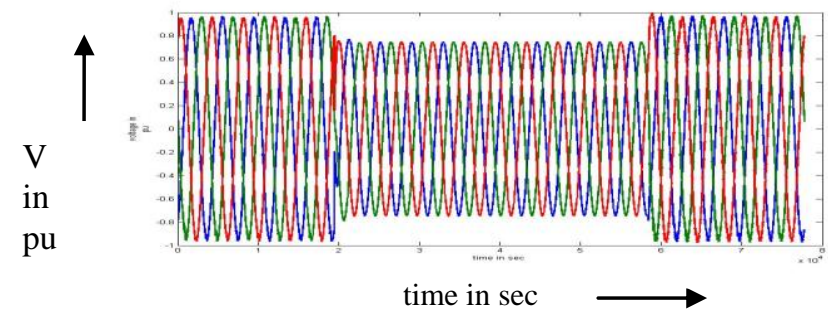

Fig.8. Voltage sag in feeder 1.

The voltage sag waveform in feeder 2 is shown in fig.9. whenever the three phase fault occur in feeder 1 it causes the voltage sag will occur in the feeder 1 and also affect the feeder 2 . These are the problems; the voltage sag in two feeder can be mitigated simultaneously by simulating the unified power quality conditioner with IEEE 16 bus system. The compensated output voltage for feeder 1 and feeder 2 is shown in fig 11 and 12.

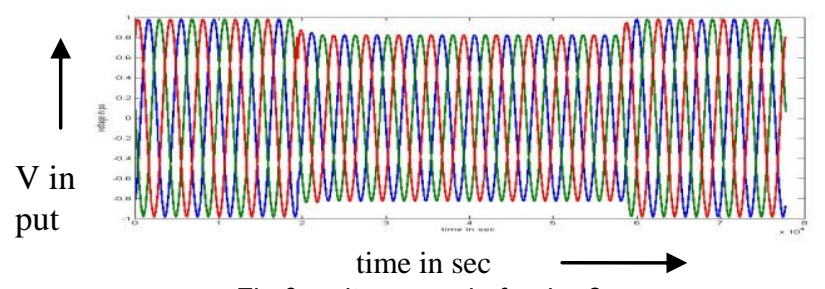

Fig.9. voltage sag in feeder 2.

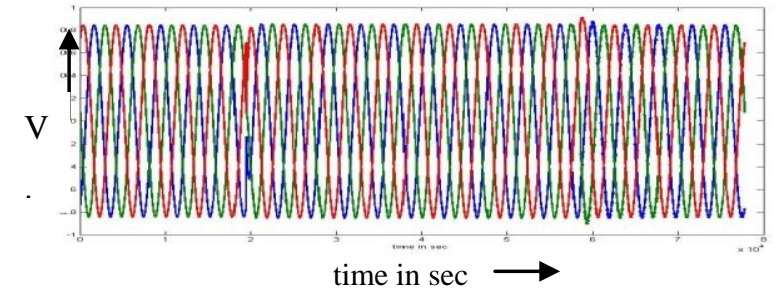

Fig.10. The compensated output voltage in Feeder 1.

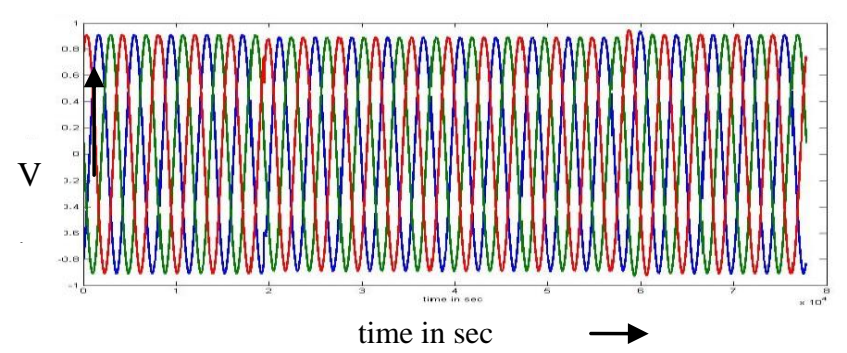

Fig.11. Compensated output voltage in a feeder 2.

Distribution system contains the many nonlinear loads it causes harmonics flow through it as shown in Fig.12.We can eliminate these harmonics using shunt VSC and get the output current is purely sinusoidal as shown in Fig.13. 


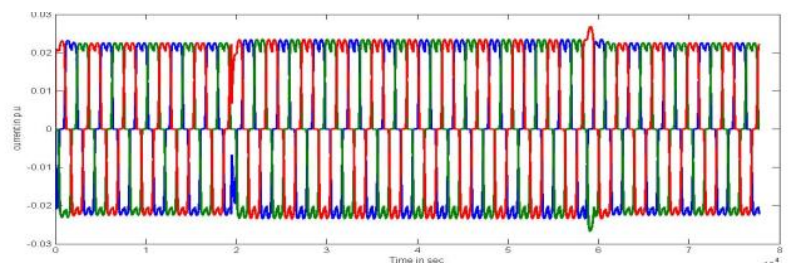

Fig.12.Current in p.u at the load point with shunt compensator

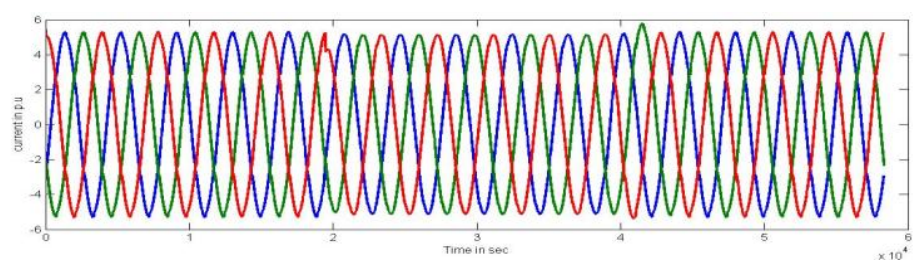

Fig.13. Current in p.u at the load point with shunt compensator

The simulation results shows that the voltage sag and unbalance of bus 1 voltage are compensated for by injecting the proper voltage by using unified power quality conditioning system.

\section{CONCLUSION}

This work presented in simulation results for a UPQC operating in a typical unbalanced distribution test system under fault condition. In this paper, a new configuration for simultaneous compensation of voltage in adjacent feeders has been proposed. The proposed topology is capable of fully protecting critical and sensitive loads against voltage sags in two-feeder systems. A commercially available UPQC topology was chosen. In addition, a pulse width modulation control system was used, in order to illustrate that the instantaneous $p-q$ Theory is widely used to design controllers for active filters.

Finally, it can be concluded that the MC- UPQC used for improvement of power quality in unbalanced distribution systems. The device is connected between two feeders coming from different substations. An unbalanced and non-linear load is supplied by Feeder-1 while a linear load is supplied through Feeder-2. The main aim of the MC-UPQC is to regulate the voltage at the terminals of Feeder-1 and to protect the sensitive load from disturbances occurring upstream. The performance of the MC-UPQC has been evaluated under various disturbance conditions such as voltage sag in either feeder, fault in one of the feeders and load change. It has been shown that in case of voltage sag, the phase angle of the bus voltage in which the shunt VSC is connected plays an important role as it gives the measure of the real power required by the load.

\section{REFERENCES}

1. João Afonso, Maurício Aredes, Edson Watanabe, Júlio Martins,"Shunt Active Filter for Power Quality Improvement", International Conference UIE 200 November 2000.

2. D.K. Tanti,Brijesh singh, Dr. M.K. Verma, Dr. O. N. Mehrotra an," ANN based approach for optimal placement of DSTATCOM for voltage sag mitigation", International journal of engineering science and technology issn :09755462 vol. 3 no. 2 feb 2011.

3. Hideaki Fujita, "The unified power quality conditioner(UPQC): the integration of series- and shuntactive filters", IEEE transactions on power electronics, march 1998.

4. C.H.Ram Jethmalani, V.Karthikeyan, and Narayanappa "Implementation of UPQC for Voltage Sag Mitigation ", International Journal of Computer Communication and Information System ( IJCCIS)July - Dec 2010.

5. Hamid Reza Mohammadi, Ali Yazdian Varjani, and Hossein Mokhtari,"Multiconverter Unified Power-Quality Conditioning System", IEEE transactions on power delivery, vol. 24, no. 3, July 2009.

6. S.V.Ravi kumar and S.Siva nagaraju" simulation of D-STATCOM and DVR in power systems", ARPN Journal of Engineering and Applied Sciences June 2007.

7. Woo Cheol Lee, Dong Myung Lee,"New control scheme for a The unified Power Quality Conditioner with minimum active power injection", IEEE Transactions on power delivery volume 25 No.2, April2010.

8. João L. Afonso, M. J. Sepúlveda Freitas, and Júlio S. Martins, Member, "Active Filters with Control Based on the p-q Theory" IEEE Industrial Electronics Society vol. 47,September. 2000.

9. S. Civanlar, J. J. Grainger, H. Yin, and S. S. H. Lee, "Distribution feeder reconfiguration for loss reduction," IEEE Trans. Power Delivery, vol. 3, pp. 1217-1223, July 1988.

10. Amit kumar Jindal,"Interline unified power quality conditioner" IEEE transactions on power delivery, vol. 22, no. 1, January 2007.

11. H. Akagi, Y. Kanazawa, A. Nabae, Generalized Theory of the Instantaneous Reactive Power in Three-Phase Circuits, IPEC'83 - Int. Power Electronics Conf., Tokyo, Japan, 1983.

12. H. Akagi, Y. Kanazawa, A. Nabae, Instanataneous Reactive Power Compensator Comprising Switching Devices without Energy Storage Compenents", IEEE Trans. Industry Applic. vol. 20, May/June 1984. 